\title{
The Newton-Raphson Method Applied to the Time-Superposed ILS for Parameter Estimation in Thermal Response Tests
}

\author{
Willem Mazzotti \\ Milan Stokuca
}

\author{
Husni Firmansyah \\ Björn Palm \\ José Acuña
}

\begin{abstract}
Thermal Response Testing is now a well-known and widely-used method allowing the determination of the local thermal or geometrical properties of a Borehole Heat Exchanger (BHE), those properties being critical in the design of GSHP systems. The analysis of TRTs is an inverse problem that has commonly been solved using an approximation of the ILS solution. To do this, however, the beat rate during a TRT must be kept constant, or least be non time-correlated, during the test, which is a challenging constraint. Applying temporal superposition to the ILS model is a way to account for varying power, although it requires the use of an optimization algorithm to minimize the error between a parametrized model and experimental values.

In this paper, the Newton-Raphson method is applied to the time-superposed ILS for parameter estimation in TRTs. The parameter estimation is limited to the effective thermal conductivity and the effective borehole resistance. Analytical expressions of the first and second derivatives of the objective function, chosen as the sum of quadratic differences, are proposed, allowing to readily inverse of the Hessian matrix and speed the convergence process.

The method is tried for 9 different TRTs, 2 of which are reference datasets used for validation of the method (Beier et al., 2010). Differences between estimated and reference thermal conductivities are of $3.4 \%$ and $0.4 \%$ for the first and second reference TRTs, respectively. The method is shown to be stable and consistent: for each of the 9 TRTs, 11 realizations are performed with different initial values. Convergence is reached in all cases and all realizations lead to the same final values for a given TRT.
\end{abstract}

The proposed convergence method is about 70\% to 90\% faster than the Nelder-Mead simplex and require about 8 times less iterations in average. The convergence speed varies between 0.3 to $13.6 \mathrm{~s}$ with an average of $3.7 \mathrm{~s}$ for all TRTs.

\section{INTRODUCTION}

Thermal Response Testing is a well-known in-situ method used to determine the local effective thermal conductivity, $\lambda^{*}$, and effective borehole thermal resistance, $R_{b}^{*}$, both parameters being critical for the design of GroundSource Heat Pump (GSHP) systems and/or Borehole Thermal Energy Storage (BTES). The Thermal Response Test (TRT) method for Borehole Heat Exchangers (BHEs) was introduced by Mogensen (1983) who discussed the experimental setup as well as the analysis procedure. The first TRT units were not specifically built to be transported and mobile units only appeared later (Eklöf \& Gehlin, 1996). Today, most TRT rigs are built as mobile units (IEA ECES Annex 21, 2013). A more detailed description of the historical development of TRT units can be found in Spitler and Gehlin (2015). TRTs are now performed worldwide for both commercial and research purposes (IEA ECES Annex 21, 2013; Spitler \& Gehlin, 2015; Witte, 2016; Zhang et al., 2014). Several developments of the TRT method have been undertaken since Mogensen's initial proposal, including:

Willem Mazzotti (willem.mazzotti@energy.kth.se) is a PhD candidate at the Royal Institute of Technology (KTH) and a consultant at the Swedish firm Bengt Dahlgren AB (willem.mazzotti@bengtdahlgren.se). Husni Firmansyah is a recently graduated student from the Royal Institute of Technology (KTH). Milan Stokuca is a consultant at Bengt Dahlgren AB. José Acuña is a PhD and researcher at the Royal Institute of Technology (KTH) as well as a manager in Bengt Dahlgren AB. Björn Palm is a professor at the Royal Institute of Technology (KTH). 
- Distributed Thermal Response Tests (DTRTs) through the use of fiber optic cables (Acuña, 2013; Fujii et al., 2009; Radioti et al., 2018; Sakata et al., 2018), wireless sensors (Martos et al., 2010) or wired sensors (Acuña, 2008; Aranzabal et al., 2016; Yu et al., 2013)

- accounting for groundwater flow on the thermal response (Molina-Giraldo et al., 2011; Raymond et al., 2011; Rivera et al., 2015; Witte, 2007)

- using different methods to calculate the average fluid temperature (Beier, 2011; Beier et al., 2012; Beier \& Spitler, 2016; Lamarche et al., 2017; Marcotte \& Pasquier, 2008)

- modified control strategies or methodologies (Choi \& Ooka, 2017; Raymond et al., 2015; Rolando, 2015; Rolando et al., 2017; Witte et al., 2002)

- estimation of uncertainties (Witte, 2013)

- definition of a criterion for the test duration (Poulsen \& Alberdi-Pagola, 2015).

New approaches for the determination of ground thermal properties have also been initiated, see for instance Raymond et al. (2016) and Raymond et al. (2017).

The analysis method initially proposed by Mogensen (1983) entailed the use of the Infinite Line Source (ILS) solution (Carslaw \& Jaeger, 1959; Ingersoll \& Plass, 1948) to evaluate the change in average fluid temperature, such that

$$
\Delta T=q\left(R_{b}^{*}+\frac{1}{4 \pi \lambda^{*}} E_{1}\left(\frac{r_{b}^{2}}{4 \alpha t}\right)\right)
$$

The exponential integral term in eq.1 may be expressed as the series expansion $E_{1}(x)=-\gamma-\ln (x)-\sum_{i=1}^{\infty} \frac{(-x)^{i}}{i \cdot i !}$ (Abramowitz \& Stegun, 1964). For relatively large values of time (small values of $x$ ), the higher order terms in the previous equation may be neglected, leading to

$$
\Delta T=q\left(R_{b}^{*}+\frac{1}{4 \pi \lambda^{*}}\left(\ln \left(\frac{4 \alpha t}{r_{b}^{2}}\right)-\gamma\right)\right)
$$

which allows the estimation of $\lambda^{*}$ and $R_{b}^{*}$ through linear regression. This method is referred to as ILS regression in the rest of this article. Note that the determination of $R_{b}^{*}$ requires knowledge of $r_{b}, \alpha$ and the undisturbed temperature. Hellström (1991) reported a maximum error of $2 \%$ for approximation (2) for $t \geq 5 r_{b}^{2} / \alpha$, which can be verified by computing the exponential integral and its approximation (2) at the given value.

The ILS model is used in more than $90 \%$ of TRTs, being by far the most common analysis method for such tests (IEA ECES Annex 21, 2013). This is likely inherent to the simplicity of the approximation shown in eq.2. However, this approximation requires having a heat rate that is, if not perfectly constant, non time-correlated. This may be hard to accomplish as noted in the literature (IEA ECES Annex 21, 2013; Spitler \& Gehlin, 2015; Zhang et al., 2014). Beier and Smith (2003) propose a way to bypass this issue by using deconvolution in the Laplace domain. The method requires knowledge of the temperature change from time zero to infinity, thus extrapolation for large times must be performed since TRTs are finite in duration. Other authors have proposed experimental methods to keep the power as constant as possible, see for instance Witte et al. (2002), Rolando (2015) and Rolando et al. (2017). The ASHRAE guidelines for TRTs recommend power variations with a standard deviation lower than $1.5 \%$ of the average value (ASHRAE, 2011). Standard deviation is however not the best metrics for power variation in TRTs as information about a potential time correlation is lost. Time-correlated variations may lead to errors in the estimation of the thermal conductivity, even with variations respecting the ASHRAE criterion.

Another way to account for varying power is to apply temporal superposition, assuming the power under a TRT can be approximated as a piecewise constant function (see eq.4). This however precludes the use the ILS regression for 
the determination of $\lambda^{*}$ and $R_{b}^{*}$, and parameter estimation has to be employed; the exponential integral approximation (2) will moreover be less accurate as the higher order terms may become significant. The full series expansion is therefore preferred when applying superposition with the ILS model. As there is no straightforward way to determine any unknown parameter, those must be estimated through the minimization of an objective function, hence an optimization problem. Choi and Ooka (2015) propose a parameter estimation method using temporal superposition with the ILS coupled to a quasi-Newton optimization algorithm. Li and Lai (2012) estimate up to 8 parameters in TRTs using the infinite cylindrical source model coupled to a Levenberg-Marquardt and a trust region method.

Parameter estimation may also be performed with numerical models (Austin, 1998; Austin, Yavuzturk, \& Spitler, 2000; Pasquier, 2015; Shonder \& Beck, 1999; Wagner \& Clauser, 2005). Jain (1999) compares up to 8 parameter estimation techniques coupled to a numerical model. The author finds that non-gradient based deterministic methods such as the Nelder-Mead simplex are faster for the considered numerical model. Numerical models are of interest as they can accurately reproduce the conditions of a TRT, hence allowing the estimation of many parameters in the model. The use of numerical models may however be computationally demanding and require case-specific adjustments. It may also be challenging to apply all of the obtained parameters during the design of the system for which the TRT is performed.

This work presents the application of the Newton-Raphson method to the time-superposed ILS for parameter estimation in TRTs. In contrast to previous studies with analytical models, the Hessian matrix is analytically determined here, meaning that an expression of the second order derivatives is analytically determined and used in the algorithm. As the estimated parameters are limited to $R_{b}^{*}$ and $\lambda^{*}$, the inverse of the Hessian matrix can be readily determined, thereby increasing the convergence speed. The convergence method is compared to the Nelder-Mead algorithm (1965) and its reliability is tested. The proposed method is validated against two reference datasets (Beier et al., 2011) and applied to 7 different commercial TRTs.

\section{METHODOLOGY}

This section is organized as such: first, the general form of the Newton-Raphson method for estimation of multiple parameters is reminded; then, the analytical expressions of the Hessian matrix elements are derived; finally, some other features of the convergence method are presented as well as the TRT datasets used in this study.

\section{Newton-Raphson method}

The Newton-Raphson method is a well-known root-finding iterative method used in engineering problems. The method is gradient-based and may be use for optimization problems. The unscaled, univariate Newton-Raphson method may be expressed as $x_{n+1}=x_{n}-\frac{f\left(x_{n}\right)}{f^{\prime}\left(x_{n}\right)}$ where $f$ is the function which root is sought (Christensen \& Bastien, 2016; Venkateshan \& Swaminathan, 2014). For multiple variables, the Newton-Raphson method may be reformulated as $\boldsymbol{x}^{(n+1)}=\boldsymbol{x}^{(n)}-\boldsymbol{J}^{-1}\left(\boldsymbol{x}^{(n)}\right) \boldsymbol{f}\left(\boldsymbol{x}^{(n)}\right)$ where $\boldsymbol{J}$ is the Jacobian matrix of the vector function $\boldsymbol{f}$ (Alart, 1997; Christensen \& Bastien, 2016). This may also be formulated as an unconstrained optimization problem by introducing an objective function, $h$, so that $\boldsymbol{\nabla} h=\boldsymbol{f}$, leading to

$$
\boldsymbol{x}^{(n+1)}=\boldsymbol{x}^{(n)}-\boldsymbol{H}^{-1}\left(\boldsymbol{x}^{(n)}\right) \boldsymbol{\nabla} h\left(\boldsymbol{x}^{(n)}\right)
$$

where $\boldsymbol{H}$ is the Hessian matrix of the function $h$, that is the matrix of the second order derivatives of the function $h$ (Keller, 2018; Pollock, 1999; Sieniutycz \& Szwast, 2018). When the expression of the second order derivatives can be determined and the inverse of the Hessian matrix made readily available, the Newton-Raphson method can be more efficient as it requires less steps to converge. In this study, the inverse of the Hessian matrix is analytically determined. The Newton-Raphson method is referred to as N-R method below. 


\section{$\mathrm{N}$-R applied to the time-superposed ILS: derivation of the inverse Hessian matrix}

Temporal superposition may be expressed for any given step response function, called here $g$, to calculate the modelled temperature change. If the power is approximated as a piecewise constant function, this change in inlet-outlet average temperature (temperature response) may be written as

$$
\Delta T_{\text {mod }}\left(t_{i}, \boldsymbol{x}\right)=(q * g)\left(t_{N}, \boldsymbol{x}\right)=\sum_{j=0}^{i-1} \Delta q_{j} \cdot g\left(t_{i}-t_{j-1}, \boldsymbol{x}\right)
$$

The specific heat rate, $q$, is either calculated from the measured flow rate and temperature difference, as well as the secondary fluid thermal properties and the borehole active depth or from the electric power input. One wants to minimize the error between experimental and modelled values by varying the parameters sought for, represented here by the vector $\boldsymbol{x}$. The minimization of the error requires the definition of an objective function, chosen here as the sum of quadratic differences

$$
h(\boldsymbol{x})=\sum_{i=N_{1}}^{N_{2}}\left(\Delta T_{m o d}\left(t_{i}, \boldsymbol{x}\right)-\Delta T_{\text {exp }}\left(t_{i}\right)\right)^{2}
$$

where $N_{1}$ and $N_{2}$ determine the optimization period. In this work, the ILS coupled to an effective resistance model is chosen as response function, leading to $g=R_{b}^{*}+\frac{1}{4 \pi \lambda^{*}} E_{1}\left(\frac{r_{b}^{2}}{4 \alpha t}\right)$. The choice of the ILS as well the limitation to $\lambda^{*}$ and $R_{b}^{*}$ is done in accordance with the state-of-the-art (IEA ECES Annex 21, 2013). It shall be noted that the ILS cannot accurately reproduce the heat transfer behavior of a borehole at short time steps. Improvements in both the model and the amount of estimated parameters are left to later investigations. To determine the Hessian matrix, $1^{\text {st }}$ and $2^{\text {nd }}$ order derivatives of the function $h$ must be determined. The 1 st order derivatives of $h$ with respect to $\boldsymbol{x}$ can be expressed as

$$
\frac{\partial h}{\partial x_{m}}(\boldsymbol{x})=2 \sum_{i=N_{1}}^{N_{2}}\left(\frac{\partial \Delta T_{m o d, i}}{\partial x_{m}}(\boldsymbol{x})\left(\Delta T_{m o d, i}(\boldsymbol{x})-\Delta T_{\text {exp }, i}\right)\right)
$$

The partial derivatives of the modelled temperature response with respect to $\lambda^{*}$ and $R_{b}^{*}$ are $\frac{\partial \Delta T_{m o d, i}}{\partial \lambda^{*}}(\boldsymbol{x})=$ $\frac{1}{4 \pi \lambda^{*}} \sum_{j=0}^{i-1} \Delta q_{i}\left(e^{-a_{i, j}}-E_{1}\left(a_{i, j}\right)\right)$ and $\frac{\partial \Delta T_{m o d, i}}{\partial R_{b}^{*}}(\boldsymbol{x})=\sum_{j=0}^{i-1} \Delta q_{j}=q\left(t_{i}\right)=q_{i}$, where $a_{i, j}=\frac{r_{b}^{2}}{4 \alpha\left(t_{i}-t_{j}\right)}$ and is dependent on $\lambda^{*}$ (and, thus, $\boldsymbol{x}$ ). After successive derivations, it can be shown that

$$
\left\{\begin{array}{c}
\frac{\partial^{2} h}{\partial \lambda^{* 2}}(\boldsymbol{x})=\frac{1}{2 \pi \lambda^{* 3}} \sum_{i=N_{1}}^{N_{2}}\left[\begin{array}{c}
\frac{1}{4 \pi \lambda^{*}}\left(\sum_{j=0}^{i-1} \Delta q_{j}\left(e^{-a_{i, j}}-E_{1}\left(a_{i, j}\right)\right)\right)^{2}+ \\
\left(\Delta T_{\text {mod, } i}(\boldsymbol{x})-\Delta T_{\text {exp }, i}\right) \sum_{j=0}^{i-1} \Delta q_{j}\left(e^{-a_{i, j}}\left(a_{i, j}-3\right)-2 E_{1}\left(a_{i, j}\right)\right)
\end{array}\right] \\
\frac{\partial^{2} h}{\partial R_{b}^{* 2}}(\boldsymbol{x})=2\left(\sum_{i=N_{1}}^{N_{2}} q_{i}\right)^{2} \\
\frac{\partial^{2} h}{\partial R_{b}^{*} \partial \lambda^{*}}(\boldsymbol{x})=\frac{\partial^{2} h}{\partial \lambda^{*} \partial R_{b}^{*}}(\boldsymbol{x})=\frac{1}{2 \pi \lambda^{* 2}} \sum_{i=N_{1}}^{N_{2}} q_{i} \sum_{j=0}^{i-1} \Delta q_{j}\left(e^{-a_{i, j}}-E_{1}\left(a_{i, j}\right)\right)
\end{array}\right.
$$


The two first terms in eq.7 are the diagonal elements of the Hessian matrix in eq.3, while the last term represents both non-diagonal elements, the matrix being symmetric. It should be noted that $\frac{\partial^{2} h}{\partial R_{b}^{* 2}}$ is a constant and does therefore not need to be reevaluated at every iteration step. One may notice redundancies in the 3 equations in 7; this observation can be used to speed the computation of the derivatives. Given the previous developments, and since the Hessian matrix is a $2 \times 2$ matrix in this case, eq. 3 may be expressed in matrix form as

$$
\boldsymbol{x}^{(n+1)}=\boldsymbol{x}^{(n)}-\frac{1}{\frac{\partial^{2} h}{\partial \lambda^{* 2}} \frac{\partial^{2} h}{\partial R_{b}^{* 2}}-\left(\frac{\partial^{2} h}{\partial R_{b}^{*} \partial \lambda^{*}}\right)^{2}}\left(\begin{array}{cc}
\frac{\partial^{2} h}{\partial R_{b}^{* 2}} & -\frac{\partial^{2} h}{\partial R_{b}^{*} \partial \lambda^{*}} \\
-\frac{\partial^{2} h}{\partial R_{b}^{*} \partial \lambda^{*}} & \frac{\partial^{2} h}{\partial \lambda^{* 2}}
\end{array}\right)\left(\begin{array}{l}
\frac{\partial h}{\partial \lambda^{*}} \\
\frac{\partial h}{\partial R_{b}^{*}}
\end{array}\right)
$$

This matricial form can be decomposed into two equations, one for each variable in $\boldsymbol{x}$, namely $\lambda^{*}$ and $R_{b}^{*}$.

Note that the positive-definiteness of the Hessian matrix is not investigated here, which entails an accurate first guess for the iterative process (Pollock, 1999). Therefore, the commonly used ILS regression, based on eq.2, is applied to find initial values of $\lambda^{*}$ and $R_{b}^{*}$.

\section{Implementation of the algorithm}

The algorithm has been implemented in both an Excel spreadsheet, through VBA (Microsoft Excel, 2016; Microsoft Visual Basic for Applications, 2012), and in $\operatorname{MATLAB}^{\circledR}(M A T L A B, 2017)$. The Matlab code is planned to be openly distributed. All the results used in this work are generated using the Matlab code.

Relative convergence criteria for $\lambda^{*}$ and $R_{b}^{*}$ are set as $0.1 \%$ for both parameters. Moreover, if the number of iterations is a multiple of 20 or if $\lambda^{*} \notin[1 ; 10] \mathrm{W} \cdot \mathrm{m}^{-1} \cdot \mathrm{K}^{-1}$ or $R_{b}^{*} \notin[0.005 ; 0.3] \mathrm{m} \cdot \mathrm{K} \cdot \mathrm{W}-1$, the next set of values for $\lambda^{*}$ and $R_{b}^{*}$ is taken around $2 \mathrm{~W} \cdot \mathrm{m}^{-1} \cdot \mathrm{K}^{-1}$ and $0.05 \mathrm{~m} \cdot \mathrm{K} \cdot \mathrm{W}^{-1}$, respectively, with random variations of 50 to $150 \%$.

\section{Used TRT data}

Data from 7 different commercial TRTs and two reference TRT datasets (Beier et al., 2011) are used in this work.

For the commercial TRTs, the used units are as described in Kamarad (2012) for TRT-1 and as described in Olausson (2018) for the remaining TRTs. For the first TRT, data is recorded about every 30 seconds whereas data is averaged over a span of 10 minutes for the remaining TRTs. The power is calculated using the measured temperature difference, the measured flow rate and thermal properties derived from Melinder (2007). All boreholes are filled with groundwater.

The two reference TRT datasets are directly taken from Beier et al. (2011) and referred to as TRT-B1 and TRTB2. The two TRTs are performed under controlled conditions in the same grouted borehole. The first is a "constant heat input rate test" with "variations well within the guidelines suggested by ASHRAE". The second TRT is an interrupted test having a power outage between 9 and 11 hours after start. For more details about the reference datasets, the readers are referred to Beier et al. (2011). These datasets are used to validate the ILS model coupled to the N-R algorithm.

The flow and heat rate (power) for all TRTs are reported in Figure 1 while fixed parameters are reported in Table 1. It should be noted that for TRT-B2, the undisturbed temperature is approximated as the return temperature after 3 min, which is the closest lower time bound to the residence time. This is done because data shows some heat injection already at the very start of the test; moreover, the initial fluid temperature is about $1.5 \mathrm{~K}$ lower than the temperature in the sand. Figure 1 highlights the difficulties in keeping of constant heat rates during TRTs. 


\section{RESULTS}

\section{Optimization process, consistency and stability}

The optimization procedure converges for all TRTs with a number of iterations varying between 2 to 8 . The optimization process for TRT-1 is displayed in Figure 2, which shows an enlarged (a) and a zoomed view (b) of the optimization domain.

To try the consistency and stability of the algorithm, different initial values are tried for all the TRTs. What is meant here with consistency and stability is the consistency in the obtained final values and the stability in the algorithm convergence. For each TRT, 10 randomly chosen initial vector values $\left(\lambda^{*(0)}, R_{b}^{*}{ }^{(0)}\right)$ in the range $[1 ; 10] \mathrm{W} \cdot \mathrm{m}^{-1} \cdot \mathrm{K}^{-1} \times$ $[0.005 ; 0.3] \mathrm{m} \cdot \mathrm{K} \cdot \mathrm{W}^{-1}$ are tried together the $\mathrm{N}-\mathrm{R}$ convergence algorithm. In total, 99 optimization procedures are run, including those with initial vectors obtained through the ILS regression. All optimization procedures converge and, for a given TRT, the results are the same independently of the initial values (maximum difference of $0.5 \%$ ). This result is important as the existence of a valley of low values for the objective function has been pointed out in the literature (Jain, 1999; Marcotte \& Pasquier, 2008; Spitler \& Gehlin, 2015; Witte et al., 2002).

The validation of the time-superposed ILS model coupled with N-R algorithm is performed using the reference thermal conductivity and borehole thermal resistance provided in Beier et al. (2011). The results and reference values are presented in Table 2.

Table 1. TRT fixed parameters

\begin{tabular}{cccccccccc}
\hline Parameters & TRT-1 & TRT-2 & TRT-3 & TRT-4 & TRT-5 & TRT-6 & TRT-7 & TRT-B 1 & TRT-B2 \\
\hline \hline Borehole diameter [m] & 0.12 & 0.115 & 0.115 & 0.115 & 0.115 & 0.115 & 0.115 & 0.126 & 0.126 \\
Active borehole length [m] & 331.7 & 324.8 & 298.2 & 296.2 & 122 & 297.3 & 230.3 & 18.3 & 18.3 \\
Optimization start [hrs] & 65 & 21 & 25 & 17 & 17 & 45 & 27 & 10 & 40 \\
Optimization stop [hrs] & 119 & 66 & 70 & 117 & 75 & 80 & 62 & 51.5 & 50 \\
$\boldsymbol{T}_{\mathbf{0}}\left[{ }^{\circ} \mathbf{C}\right]$ & 8.60 & 9.97 & 9.30 & 9.59 & 10.53 & 9.77 & 8.50 & 22.00 & 21.53 \\
\hline
\end{tabular}

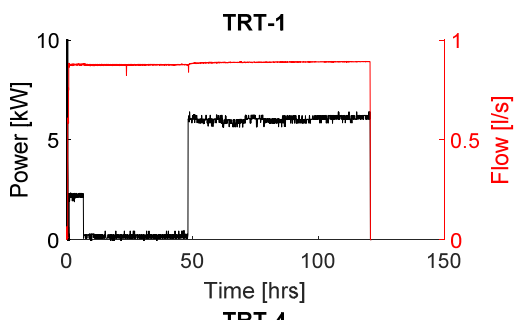

TRT-4
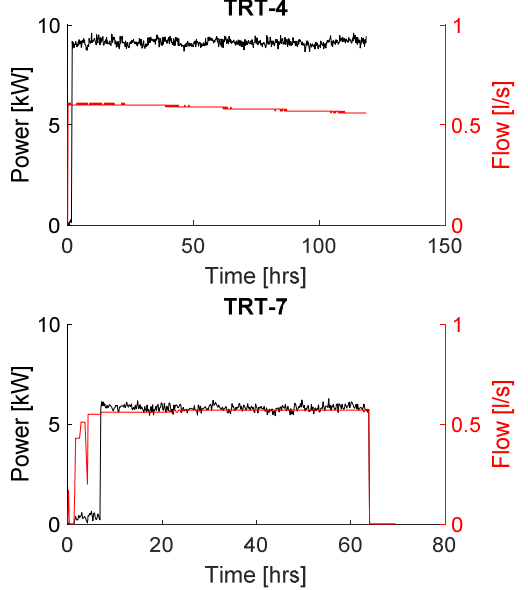
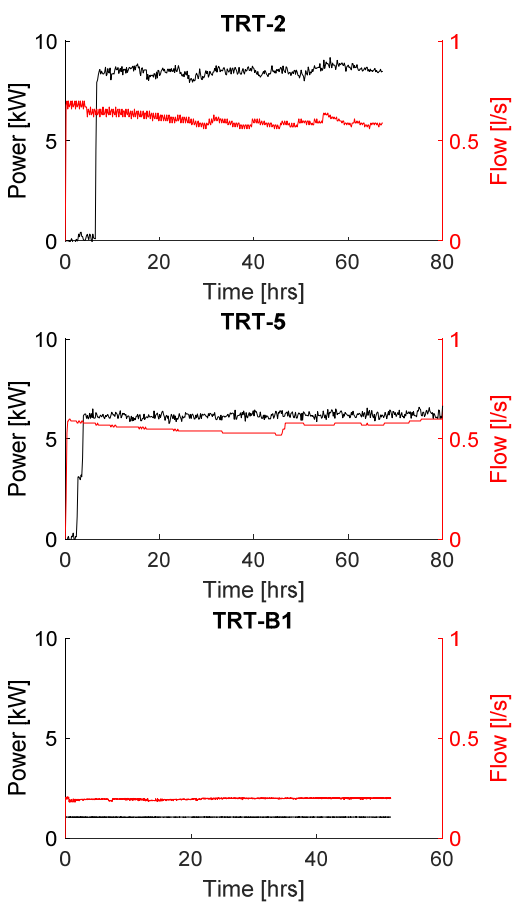

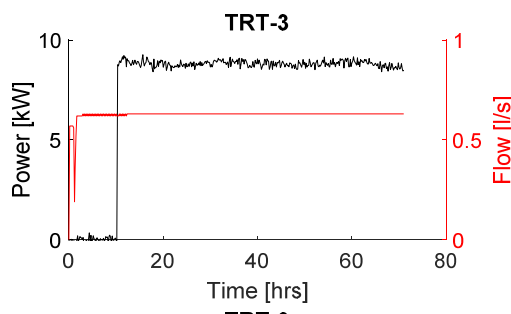

TRT-6
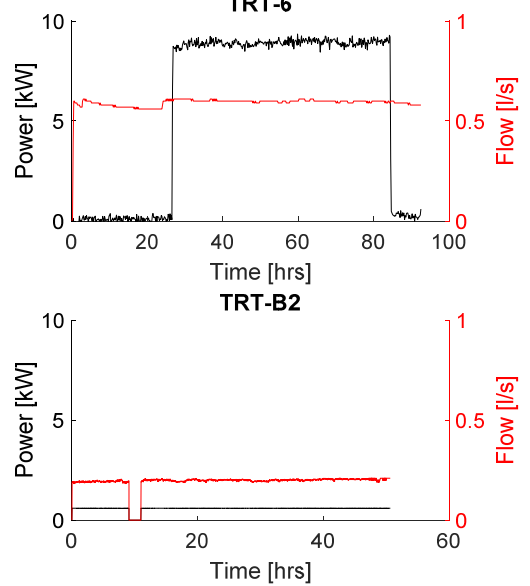

Figure 1. Power and flow rates during the 9 different TRTs used for this study 


\section{Comparison between the $\mathbf{N}-\mathbf{R}$ and the Nelder-Mead algorithms}

In order to evaluate the convergence speed of the N-R algorithm, the latter is compared with the Nelder-Mead algorithm (1965) as implemented in Matlab through the function fminsearch. The presented N-R method is always faster than the Nelder-Mead method with convergence durations between 70 to $92 \%$ lower. In average, the Nelder-Mead method leads to about 8 times more iterations than the N-R method. This comforts the statement from Choi and Ooka (2015) that the Nelder-Mead simplex is not the most suitable method for ILS parameter estimation in TRTs.

The average convergence speed for all TRTs is of $3.7 \mathrm{~s}$ with the Newton-Raphson method (CPU: $2.60 \mathrm{GHz}$, RAM: 16 GB). The N-R and Nelder-Mead convergence speeds for each TRT are reported in Table 2, as well as the index of the last point $\left(N_{2}\right)$ and number of points in the optimization period.
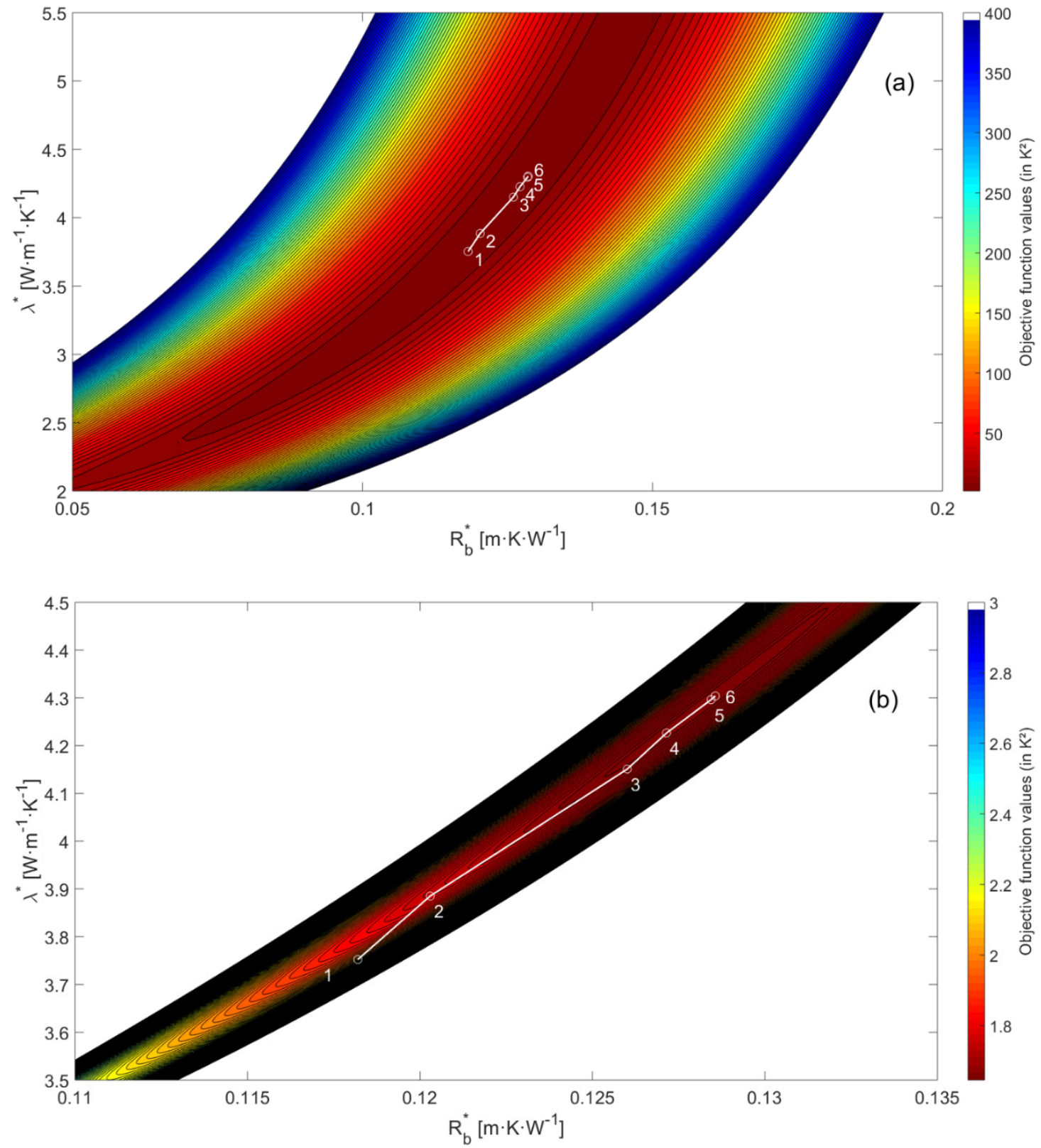

Figure 2. Optimization procedure for TRT-1: in an enlarged (a) and zoomed view (b) of the optimization domain. 


\section{Temperature response: models vs measurement}

The obtained temperature responses are presented in Figure 3 against measured data for the 9 different TRTs. It can be observed that the time-superposed ILS generally overestimates the temperature response at the beginning of the heat injection. This is likely due to the quasi-steady-state assumption of the model that is not valid at early times. The overestimation seems to be more pronounced for grouted (TRT-B1-2) than water-filled boreholes (TRT-1-7). The agreement between the optimized and experimental responses is nonetheless good over the optimization periods with RMSEs no higher than $0.0765 \mathrm{~K}$ as can be seen in Table 2. This table also includes the initial (ILS regression) and final values obtained for each TRT using the N-R algorithm, as well as reference values of $\lambda^{*}$ and $R_{b}^{*}$ for TRT-B1 and TRTB2 (Beier et al., 2011). For TRT-B1, the ILS regression and the time-superposed ILS show similar $\lambda^{*}$ and $R_{b}^{*}$ values that are slightly different from the reference values, although the difference between $\lambda^{*}$ values is comprised within the $5 \%$ uncertainty of the independent measurement. For TRT-B2 however, the time-superposed ILS leads to a $\lambda^{*}$ similar to the reference value whereas the ILS regression leads to a $\lambda^{*}$ that is $7.8 \%$ higher than the reference value. The ILS regression nevertheless seems to give a slightly better estimation of $R_{b}^{*}$ in TRT-B2 with a resulting value $1.1 \%$ higher than the reference against $1.7 \%$ lower for the time-superposed ILS.

For TRT 1 to 7, differences between the results obtained with the ILS regression and the time-superposed ILS may be observed although it is not possible to determine which value is closer to the true value.
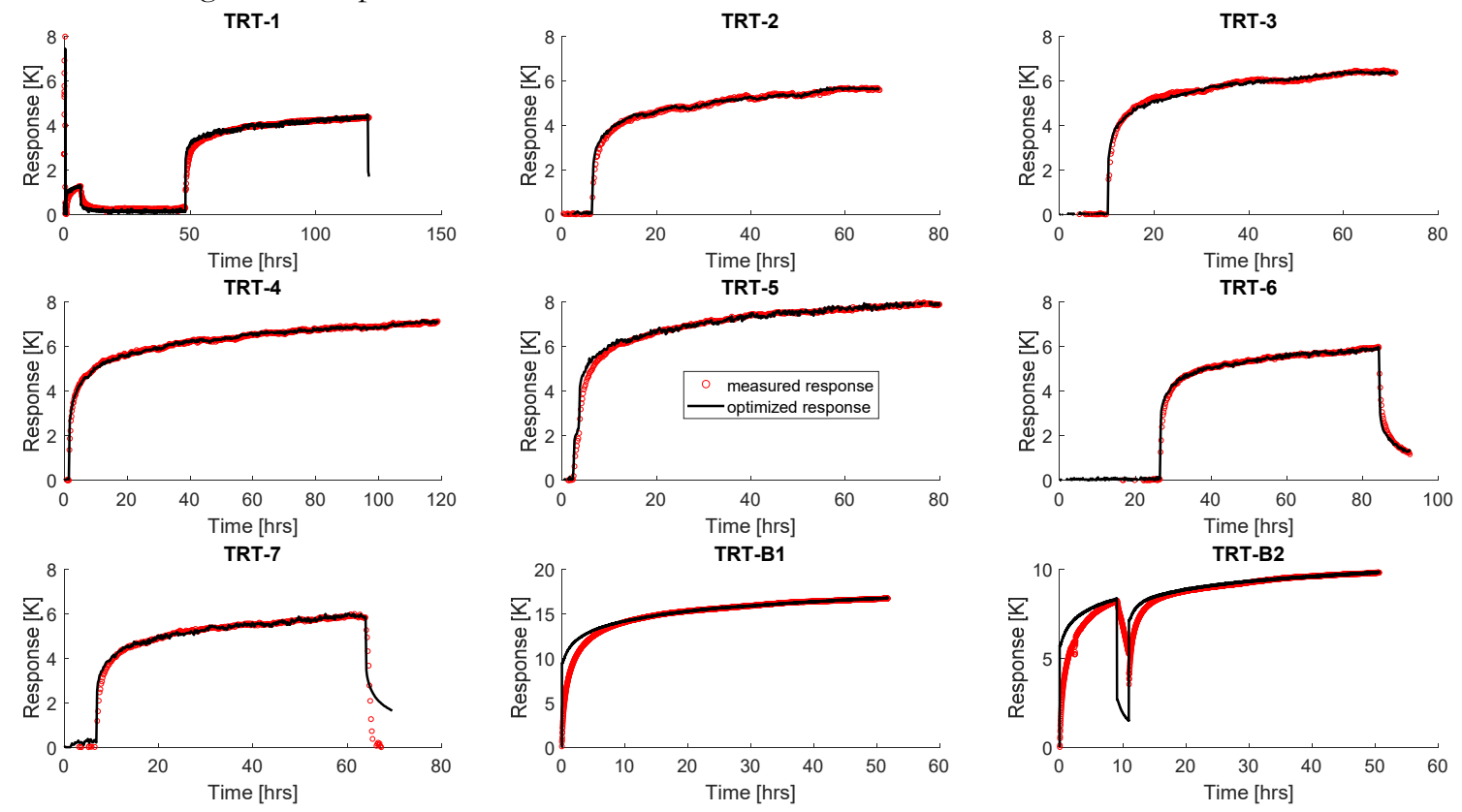

Figure 3. Measured and optimized thermal responses during the 9 TRTs used for this study

Table 2. TRT optimization results

\begin{tabular}{ccccccccccc}
\hline \multicolumn{2}{c}{ Parameters } & TRT-1 & TRT-2 & TRT-3 & TRT-4 & TRT-5 & TRT-6 & TRT-7 & TRT-B1 & TRT-B2 \\
\hline \hline Newton- & $\boldsymbol{\lambda}^{*}\left[\mathbf{W} \cdot \mathbf{m}^{-1} \cdot \mathbf{K}^{-1}\right]$ & 4.30 & 3.18 & 3.05 & 3.08 & 5.12 & 4.26 & 2.92 & 2.92 & 2.83 \\
Raphson & $\boldsymbol{R}_{\boldsymbol{b}}^{*}\left[\mathbf{m} \cdot \mathbf{K}^{-1} \cdot \mathbf{W}^{-1}\right]$ & 0.129 & 0.080 & 0.079 & 0.074 & 0.061 & 0.091 & 0.090 & 0.164 & 0.175 \\
\hline Reference & $\boldsymbol{\lambda}^{*}\left[\mathbf{W} \cdot \mathbf{m}^{-1} \cdot \mathbf{K}^{-1}\right]$ & - & - & - & - & - & - & - & 2.82 & 2.82 \\
values & $\boldsymbol{R}_{\boldsymbol{b}}^{*}\left[\mathbf{W} \cdot \mathbf{m}^{-1} \cdot \mathbf{K}^{-1}\right]$ & - & - & - & - & - & - & - & 0.173 & 0.178 \\
\hline \multirow{2}{*}{ ILS reg. } & $\boldsymbol{\lambda}^{*}\left[\mathbf{W} \cdot \mathbf{m}^{-1} \cdot \mathbf{K}^{-1}\right]$ & 3.75 & 2.77 & 3.18 & 3.14 & 4.66 & 4.10 & 3.05 & 2.91 & 3.04 \\
& $\boldsymbol{R}_{\boldsymbol{b}}^{*}\left[\mathbf{W} \cdot \mathbf{m}^{-1} \cdot \mathbf{K}^{-1}\right]$ & 0.118 & 0.066 & 0.083 & 0.076 & 0.054 & 0.087 & 0.095 & 0.164 & 0.180 \\
\hline \multicolumn{2}{r}{ Time $\mathbf{N}-\mathbf{R}[\mathbf{s}]$} & 4.8 & 0.3 & 0.3 & 0.5 & 0.7 & 0.4 & 0.3 & 13.6 & 12.7 \\
\hline
\end{tabular}




\begin{tabular}{cccccccccc}
\hline Time Nelder-Mead [s] & 24.7 & 1.6 & 1.5 & 5.4 & 2.4 & 1.6 & 1.2 & 158.3 & 78.7 \\
Index of the last point $\left(\boldsymbol{N}_{\mathbf{2}}\right)$ & 1476 & 397 & 421 & 703 & 451 & 481 & 373 & 2816 & 3001 \\
Number of points & 620 & 271 & 271 & 601 & 349 & 211 & 211 & 2246 & 601 \\
RMSE [K] & 0.0516 & 0.0618 & 0.0707 & 0.0430 & 0.0765 & 0.0509 & 0.0591 & 0.0486 & 0.0306 \\
\hline
\end{tabular}

\section{CONCLUSION AND FUTURE WORK}

This work presents the application of the Newton-Raphson optimization method to the time-superposed ILS for parameter estimation in TRTs. The time-superposed ILS is chosen so that non randomly-varying heat rates during TRTs can be considered, as opposed to the ILS regression. The ILS regression is nevertheless used to obtain the initial values for the Newton-Raphson procedure. The vector of estimated parameters is limited to $\lambda^{*}$ and $R_{b}^{*}$ and the inverse Hessian matrix is analytically determined, meaning that expressions of the second order derivatives of the sum of quadratic differences are proposed. The method is tested in 9 different TRTs, 2 of which are reference datasets used for validation of the method (Beier et al., 2010). For the first reference dataset, a constant heat rate TRT, the estimated $\lambda^{*}$ and $R_{b}^{*}$ are respectively $3.4 \%$ and $5.2 \%$ off the reference values. For the second, interrupted TRT, the differences drop to $0.4 \%$ and $1.7 \%$, respectively.

The applied Newton-Raphson method is shown to be stable and consistent. For each of the 9 TRTs, 11 realizations are performed, 10 of which have randomly-picked initial values. Convergence is reached in all cases and all realizations lead to the same final values for a given TRT.

The proposed convergence method is about $70 \%$ to $90 \%$ faster than the Nelder-Mead simplex (1965) and require about 8 times less iterations in average. The convergence speed varies between 0.3 to $13.6 \mathrm{~s}$ with an average of $3.7 \mathrm{~s}$ for all TRTs.

The agreement between optimized and experimental responses is good with RMSEs no higher than $0.0765 \mathrm{~K}$ over the optimization periods. The time-superposed ILS overestimates the temperature response at the beginning of the TRTs, likely because of the quasi-steady-state assumption of the model, which is not valid at early times. The overestimation seems to be more pronounced for grouted than water-filled boreholes.

The developed optimization method could be further improved by including more parameters to be estimated, improving the convergence criterion, and adding constraints to the objective function.

\section{ACKNOWLEDGMENTS}

This work is financed by the Swedish Energy Agency through the EFFSYS Expand program. The authors thank all the sponsors involved in the project with a special mention to Bengt Dahlgren $\mathrm{AB}$ and Finspångs Brunnsborrning $\mathrm{AB}$ that provided TRT data and helped with the processing.

\section{NOMENCLATURE}

$$
\begin{aligned}
& E_{1}=\text { Exponential integral }(-) \\
& g=\text { Step response function }\left(\mathrm{m} \cdot \mathrm{K} \cdot \mathrm{W}^{-1}\right) \\
& \boldsymbol{H}=\text { Hessian matrix } \\
& h=\text { Objective function }\left(\mathrm{K}^{2}\right) \\
& \boldsymbol{J}=\text { Jacobian matrix } \\
& N=\text { Number of points }(-) \\
& q=\text { Specific heat load }\left(\mathrm{W} \cdot \mathrm{m}^{-1}\right) \\
& \Delta q=\text { Step in specific heat load }\left(\mathrm{W} \cdot \mathrm{m}^{-1}\right) \\
& R=\text { Borehole thermal resistance }\left(\mathrm{m} \cdot \mathrm{K} \cdot \mathrm{W}^{-1}\right) \\
& r=\text { Borehole radius }(\mathrm{m})
\end{aligned}
$$

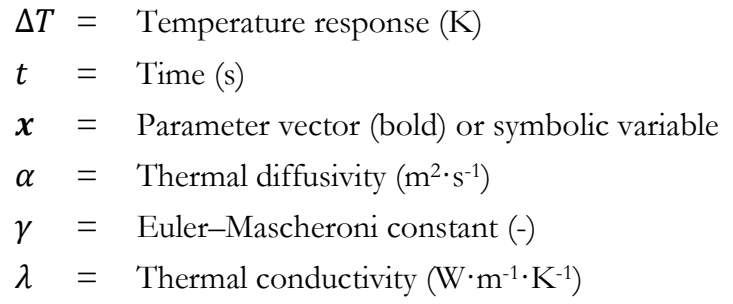

\section{Superscripts /subscripts}

$\begin{aligned} * & =\text { Effective } \\ (k) & =\mathrm{k}^{\text {th }} \text { iteration } \\ \bmod & =\text { Model } \\ \exp & =\text { Experimental }\end{aligned}$




\section{REFERENCES}

Abramowitz, M., \& Stegun, I. A. (1964). Handbook of Mathematical Functions With Formulas, Graphs, and Mathematical Tables. United States Department of Commerce, National Bureau of Standards.

Acuña, J. (2008). Characterization and Temperature Measurement Techniques of Energy Wells for Heat Pumps (Licentiate Thesis). M. Sc. Thesis, KTH School of Industrial Engineering and Management Division of Applied Thermodynamic and Refrigeration, Stockholm, Sweden.

Acuña, J. (2013). Distributed thermal response tests: new insights on U-pipe and Coaxial heat exchangers in groundwaterfilled boreholes (PhD Thesis). KTH Royal Institute of Technology, Stockholm.

Alart, P. P. (1997). Méthode de Newton généralisée en mécanique du contact. Journal de Mathématiques Pures et Appliquées, 76(1), 83-108. https://doi.org/10.1016/S0021-7824(97)89946-1

Aranzabal, N., Martos, J., Montero, Á., Monreal, L., Soret, J., Torres, J., \& García-Olcina, R. (2016). Extraction of thermal characteristics of surrounding geological layers of a geothermal heat exchanger by 3D numerical simulations. Applied Thermal Engineering, 99, 92-102. https://doi.org/10.1016/j.applthermaleng.2015.12.109

ASHRAE. (2011). 2011 ASHRAE Handbook: HVAC Applications (SI Edition). Atlanta: ASHRAE. Retrieved from http://app.knovel.com/hotlink/toc/id:kpASHRAE61/2011-ashrae-handbook

Austin, W. A. (1998). Development of an In-Situ System and Analysis Procedure for Measuring Ground Thermal Properties (Master Thesis). Stillwater, Oklahoma: Oklahoma State University.

Austin, W. A., Yavuzturk, C., \& Spitler, J. D. (2000). Development of an in-situ system for measuring ground thermal properties. ASHRAE Transactions, 106(1), 365-379.

Beier, R. A., \& Smith, M. D. (2003). Removing variable heat rate effects from borehole tests (Vol. 109 PART 2, pp. 463474). Presented at the ASHRAE Transactions.

Beier, R. A., Smith, M. D., \& Spitler, J. D. (2011). Reference data sets for vertical borehole ground heat exchanger models and thermal response test analysis. Geothermics, 40(1), 79-85. https://doi.org/10.1016/j.geothermics.2010.12.007

Carslaw, H. S., \& Jaeger, J. C. (1959). Conduction of heat in solids. Retrieved from http://adsabs.harvard.edu/abs/1959chs..book.....C

Choi, W., \& Ooka, R. (2015). Interpretation of disturbed data in thermal response tests using the infinite line source model and numerical parameter estimation method. Applied Energy, 148, 476-488. https://doi.org/10.1016/j.apenergy.2015.03.097

Christensen, J., \& Bastien, C. (2016). Chapter | three - Introduction to General Optimization Principles and Methods. In Nonlinear Optimization of Vehicle Safety Structures (pp. 107-168). Oxford: Butterworth-Heinemann. https://doi.org/10.1016/B978-0-12-417297-5.00003-1

Eklöf, C., \& Gehlin, S. (1996). TED - a mobile equipment for thermal response test : testing and evaluation. Retrieved from http://urn.kb.se/resolve?urn=urn:nbn:se:ltu:diva-59091

Fujii, H., Okubo, H., Nishi, K., Itoi, R., Ohyama, K., \& Shibata, K. (2009). An improved thermal response test for U-tube ground heat exchanger based on optical fiber thermometers. Geothermics, 38(4), 399-406. https://doi.org/10.1016/j.geothermics.2009.06.002

Hellström, G. (1991). Ground heat storage : thermal analyses of duct storage systems (PhD Thesis). Lund University, Lund, Sweden.

IEA ECES Annex 21. (2013). IEA ECES 2013 Annex21 Thermal Response Test Final Report. International Energy Agency. Retrieved from http://media.geoenergicentrum.se/2017/11/IEA_ECES_2013_Annex21_FinalReport.pdf

Ingersoll, L. R., \& Plass, H. J. (1948). Theory of the ground pipe heat source for the heat pump. ASHVE Transactions, 54(7), 339-348.

Jain, N. K. (1999). Parameter Estimation of Ground Thermal Properties (Master Thesis). Oklahoma State University.

Kamarad, A. (2012). Design and construction of a mobile equipment for thermal response test in borehole heat exchangers. Retrieved from http://urn.kb.se/resolve?urn=urn:nbn:se:kth:diva-99558

Keller, A. A. (2018). Chapter 1 - Elements of Mathematical Optimization. In Mathematical Optimization Terminology (pp. 1-12). Academic Press. https://doi.org/10.1016/B978-0-12-805166-5.00001-0

Li, M., \& Lai, A. C. K. (2012). Parameter estimation of in-situ thermal response tests for borehole ground heat exchangers. International Journal of Heat and Mass Transfer, 55(9), 2615-2624. https://doi.org/10.1016/j.ijheatmasstransfer.2011.12.033 
Marcotte, D., \& Pasquier, P. (2008). On the estimation of thermal resistance in borehole thermal conductivity test. Renewable Energy, 33(11), 2407-2415. https://doi.org/10.1016/j.renene.2008.01.021

MATLAB. (2017). (Version b). MathWorks.

Melinder, A. (2007). Thermophysical Properties of Aqueous Solutions Used as Secondary Working Fluids (PhD Thesis). Retrieved from http://urn.kb.se/resolve?urn=urn:nbn:se:kth:diva-4406

Microsoft Excel. (2016). Microsoft Corporation.

Microsoft Visual Basic for Applications. (2012). (Version 7.1). Microsoft Corporation.

Mogensen, P. (1983). Fluid to duct wall heat transfer in duct system heat storages (pp. 652-657). Presented at the International conference on subsurface heat storage in theory and practice, Stockholm, Sweden: Swedish Council for Building Research.

Nelder, J. A., \& Mead, R. (1965). A Simplex Method for Function Minimization. The Computer Journal, 7(4), $308-313$. https://doi.org/10.1093/comjnl/7.4.308

Olausson, L. (2018). Construction and test of a new compact TRT equipment. Retrieved from http:/ / urn.kb.se/resolve?urn=urn:nbn:se:kth:diva-226294

Pasquier, P. (2015). Stochastic interpretation of thermal response test with TRT-SInterp. Computers \& Geosciences, 75(Supplement C), 73-87. https://doi.org/10.1016/j.cageo.2014.11.001

Pollock, D. S. G. (1999). Chapter 12 - Unconstrained Optimisation. In Handbook of Time Series Analysis, Signal Processing, and Dynamics (pp. 323-361). London: Academic Press. https://doi.org/10.1016/B978-012560990-6/50014-2

Poulsen, S. E., \& Alberdi-Pagola, M. (2015). Interpretation of ongoing thermal response tests of vertical (BHE) borehole heat exchangers with predictive uncertainty based stopping criterion. Energy, 88, 157-167. https://doi.org/10.1016/j.energy.2015.03.133

Radioti, G., Cerfontaine, B., Charlier, R., \& Nguyen, F. (2018). Experimental and numerical investigation of a long-duration Thermal Response Test: Borehole Heat Exchanger behaviour and thermal plume in the heterogeneous rock mass. Geothermics, 71, 245-258. https://doi.org/10.1016/j.geothermics.2017.10.001

Raymond, J., Lamarche, L., \& Malo, M. (2016). Extending thermal response test assessments with inverse numerical modeling of temperature profiles measured in ground heat exchangers. Renewable Energy, 99, 614-621. https://doi.org/10.1016/j.renene.2016.07.005

Raymond, J., Malo, M., Lamarche, L., Lorenzo Perozzi, Gloaguen, E., \& Begin, C. (2017). New Methods to Spatially Extend Thermal Response Test Assessments. http://dx.doi.org/10.22488/okstate.17.000519

Rolando, D. (2015, April). Modelling of temperature responsefactors and experimental techniques for borehole heat exchanger design in geothermal heat pump applications.pdf ( $\mathrm{PhD}$ Thesis). University of Genova, Genova, Italy.

Rolando, D., Acuna, J., \& Fossa, M. (2017). Heat Extraction Distributed Thermal Response Test: A Methodological Approach and In-situ Experiment. http://dx.doi.org/10.22488/okstate.17.000536

Sakata, Y., Katsura, T., \& Nagano, K. (2018). Multilayer-concept thermal response test: Measurement and analysis methodologies with a case study. Geothermics, 71(Supplement C), 178-186. https://doi.org/10.1016/j.geothermics.2017.09.004

Shonder, J. A., \& Beck, J. V. (1999). Determining Effective Soil Formation Thermal Properties from Field Data Using a Parameter Estimation Technique. ASHRAE Transactions, 105, 458-466.

Sieniutycz, S., \& Szwast, Z. (2018). 1 - Outline of Classical Optimization Methods. In Optimizing Thermal, Chemical, and Environmental Systems (pp. 1-63). Elsevier. https://doi.org/10.1016/B978-0-12-813582-2.00001-X

Spitler, J. D., \& Gehlin, S. E. A. (2015). Thermal response testing for ground source heat pump systems-An historical review. Renewable and Sustainable Energy Reviews, 50, 1125-1137. https://doi.org/10.1016/j.rser.2015.05.061

Venkateshan, S. P., \& Swaminathan, P. (2014). Chapter 4 - Solution of Algebraic Equations. In Computational Methods in Engineering (pp. 155-201). Boston: Academic Press. https://doi.org/10.1016/B978-0-12-416702-5.50004-1

Wagner, R., \& Clauser, C. (2005). Evaluating thermal response tests using parameter estimation for thermal conductivity and thermal capacity. Journal of Geophysics and Engineering, 2(4), 349. https://doi.org/10.1088/1742-2132/2/4/S08

Witte, H. J., Van Gelder, G. J., \& Spitier, J. D. (2002). In situ measurement of ground thermal conductivity: a Dutch perspective. Ashrae Transactions, 108, 263.

Yu, X., Zhang, Y., Deng, N., Wang, J., Zhang, D., \& Wang, J. (2013). Thermal response test and numerical analysis based on two models for ground-source heat pump system. Energy and Buildings, 66, 657-666. https://doi.org/10.1016/j.enbuild.2013.07.074 